\title{
Ductal Carcinoma in Situ: Clinical Perspective
}

\author{
Thorsten Kühn \\ Klinik für Frauenheilkunde und Geburtshilfe, Interdisziplinäres Brustzentrum am Klinikum Esslingen, Germany
}

\section{Key Words}

Breast cancer - Ductal carcinoma in situ - Surgery .

Radiotherapy - Tamoxifen

\section{Summary}

Ductal carcinoma is situ (DCIS) is the fastest growing subtype of breast cancer, mainly because of improved screening activities. In contrast to invasive disease, DCIS is a local process with excellent survival rates. Current treatment strategies include surgery, radiotherapy (RT) and anti-hormonal treatment. The selection of an individual risk-adapted therapeutic approach remains controversial. This relates especially to the extent of surgery and the therapeutic index of adjuvant RT and tamoxifen. Several new trials have been published or updated recently that address important clinical issues. There is an urgent need to get more insight into the biological behaviour of different subtypes of DCIS, and develop more targeted and individualized treatment strategies. So far, surgery appears to be the most effective treatment modality. A morphology-based treatment model that allows complete resection of certain DCIS lesions without further adjuvant measures has not been evaluated prospectively and deserves further evaluation.

\section{Introduction}

Ductal carcinoma in situ (DCIS) is a heterogenous group of non-invasive breast lesions with different genetic, clinical, morphological and biological features. The tumour cells are restricted to the ductal-lobular units and have not invaded beyond the basement membrane. DCIS is a non-obligate precursor of invasive disease. A rate of $14-53 \%$ for progression

\author{
Schlüsselwörter \\ Mammakarzinom - Duktales Carcinoma in situ . \\ Operation · Strahlentherapie · Tamoxifen
}

\section{Zusammenfassung}

Durch die Zunahme des Mammographiescreenings ist eine stark wachsende Inzidenz des duktalen Carcinoma in situ (DCIS) zu verzeichnen. Im Gegensatz zum invasiven Mammakarzinom stellt das DCIS eine lokale Erkrankung mit ausgezeichneten Überlebensraten dar. Derzeitige Behandlungsstrategien beinhalten die operative Sanierung sowie die Strahlentherapie und die antihormonelle Behandlung. Die Auswahl von angemessenen und individualisierten Therapiekonzepten wird weiterhin kontrovers diskutiert. Dabei stehen die Ausdehnung der Operation und der therapeutische Index von Strahlentherapie und Tamoxifen im Fokus der Diskussion. Mehrere Studien wurden in jüngster Zeit publiziert oder aktualisiert, die wichtige klinische Fragestellungen beantworten. Es besteht ein hoher Bedarf, weitere Kenntnisse über das biologische Verhalten verschiedener Subtypen des DCIS zu erlangen, um individualisiertere und zielgerichtetere Behandlungskonzepte zu entwickeln. Derzeit stellt die operative Sanierung die effektivste Therapiemodalität dar. Morphologisch orientierte Operationsstrategien, die eine komplette lokale Exzision bestimmter Läsionen ermöglichen, wurden bis heute noch nicht ausreichend untersucht und sollten weiter evaluiert werden.

to invasive cancer has been reported with a strong association with the biological characteristics of the lesion (e.g. high grade vs. non-high grade) [1-3]. Reliable predictors to determine the individual risk of progression are not available. Risk factors for developing DCIS are similar to invasive cancer, including a family history of breast cancer, prior breast biopsies, nulliparity and late age of first pregnancy [4]. DCIS is (in general) a clinically occult lesion. Its detection depends on

\section{KARGER}

Fax +497614520714

Information@Karger.de

www.karger.com (c) 2010 S. Karger GmbH, Freiburg

Accessible online at:

www.karger.com/brc 
screening activities and the ability of imaging procedures (mainly mammography) to identify the disease. The identification and treatment of DCIS can prevent the development of invasive cancer and thus reduce breast cancer mortality. The detection of DCIS has increased considerably from 1 to $>20 \%$ since the introduction of mammography screening programmes [5, 6]. The long-term prognosis of the disease is excellent with survival rates exceeding $95 \%$ at 10 years $[7,8]$. However, $50 \%$ of recurrences are invasive, thus underlining the importance of an effective treatment and careful monitoring.

\section{Detection and Localisation}

DCIS is usually detected by mammography screening, particularly in the form of microcalcifications. To date, mammography is the only imaging modality that is routinely used to screen patients for DCIS. Histology is obtained by imageguided breast biopsy. Stereotactic vacuum-assisted core biopsy has evolved as the standard procedure. Specimen radiography is essential to prove correct tissue sampling (proof of microcalcifications).

A preoperative conference between radiologist, pathologist and breast surgeon can ensure radiographic/ histopathologic correlation. Wire localisation of the lesion is required since DCIS is (in general) not palpable. Volume planning is essential for the surgeon to avoid over- and undertreatment (unfavourable cosmetic outcome, re-excisions) and to plan an adequate reconstruction of the breast defect. Several wires may be helpful to locate the target volume in lesions exceeding $3 \mathrm{~cm}$. Intraoperative specimen radiography (in two planes) is mandatory to ensure complete resection of the target lesion and to avoid secondary interventions.

The role of magnetic resonance imaging (MRI) for the diagnosis und treatment of DCIS has been discussed most recently [9-11]. Some data suggest a higher sensitivity for MRI compared to mammography. The positive predictive value for both techniques, however, appears similar due to an unfavourable false-positive rate of MRI. Furthermore, MRI does not allow targeted tissue sampling with specimen imaging. This relates to breast biopsies for diagnostic purposes as well as to the intraoperative assessment of resection margins. A multi-wire localisation to define the resection volume appears critical with MRI. Further studies are needed to define the role of MRI in the diagnosis and treatment of DCIS.

\section{Prognostic and Predictive Factors}

The prognosis of adequately treated DCIS is excellent with survival rates of almost $100 \%$ [7, 8]. The knowledge on the biological behaviour of DCIS and its potential to progress, recur or respond to specific therapeutic options is still re- stricted. Some clinical and histopathologic factors correlate with preinvasive or invasive recurrence for patients who underwent breast conserving therapy (BCT) [12-15]: i) involved resection margins; ii) residual microcalcifications; iii) extent of the lesion; iv) young age ( $<40$ years); v) presence of comedonecrosis; vi) high grade lesions; and vii) solid growth pattern. The individual benefit from specific adjuvant treatment measures (radiotherapy (RT), tamoxifen) cannot be defined. The presence of high risk factors does not necessarily correlate with the effect of a specific adjuvant treatment [16]. Oestrogen receptor (ER) status has been identified as the only predictive factor in DCIS (for the effect of tamoxifen) [17]. Determination of the ER status is therefore mandatory before starting antihormonal treatment.

\section{Local Treatment}

In contrast to invasive breast cancer, DCIS is not regarded as a systemic disease but as a local process. The primary goal in the treatment of DCIS is the prevention of local recurrences. The intention of surgery is a complete resection of the lesion. Adjuvant local (RT) or systemic (tamoxifen) treatment can be helpful to reduce local recurrences and contralateral events. The individual benefit from adjuvant treatment is intensively debated. A close interdisciplinary cooperation between radiologist, breast surgeon, pathologist, radiooncologist and medical oncologist is mandatory for the effective treatment of DCIS. The challenge is to balance effective treatment (avoidance of recurrence, especially invasive disease) with unnecessary overtreatment (morbidity and costs).

Mastectomy has been regarded as the surgical treatment of choice for a long time. BCT has become the preferred treatment today with local recurrence rates of $9-25 \%$ and an identical survival rate as mastectomy $[18,19]$. Only patients with an unfavourable lesion/breast size ratio are candidates for mastectomy. Adequate resection volume and required width of tumour-free margins have been debated for a long time. Some surgeons define tumour-free margins as a 'complete excision'. Others aim at an excision of the entire lesion including potential occult tumour cell deposits. This philosophy includes the option of a surgical cure of DCIS without any further adjuvant treatment, and requires a strict orientation of all diagnostic and therapeutic procedures on the histopathologic growth pattern of DCIS.

Faverly et al. [20] have shown in a series of 60 whole breast examinations that DCIS was a unicentric, multifocal lesion. Tumour cells grow within the ductulolubular system thus showing a segmental expansion. Gaps between different foci of DCIS were $<5 \mathrm{~mm}$ in $63 \%$ of the cases. In $8 \%$ of the examined breasts the gaps were $>10 \mathrm{~mm}$. According to these data, a margin width of $10 \mathrm{~mm}$ would allow a complete resection of DCIS in $92 \%$ of the patients. The rate of potential relapses appears acceptable if recurrences derive from residual tumour 
foci. Silverstein et al. [12] examined retrospectively a series of 212 patients with DCIS treated with excision alone. Local control was excellent if margin width was $10 \mathrm{~mm}$ or more, regardless of other prognostic factors. The local recurrence risk at 8 years was 3\% and did not differ from patients who had received additional $\mathrm{RT}$. The authors concluded that margin width was the single most important factor in predicting local recurrence after excision alone for DCIS. Silverstein's morphology-based treatment model included an accurate measurement of tumour size and margins by complete examination of the entire specimen, serial sections and a threedimensional reconstruction of the lesion with a sequential series of slides [12]. The results from Silverstein et al. [12] are in contrast to the data from 4 randomized trials which showed a risk reduction of approximately $50 \%$ for local recurrences if BCT was combined with RT [13, 14, 21 ,22]. RT reduced the local recurrences from $15-20 \%$ at 5 years and $25-30 \%$ at 10 years to $5-9 \%$ and $15 \%$, respectively, in relatively unselected patients. The benefit was observed in all examined subgroups (clear margins vs. not, age $>50$ years vs. $<50$ years, comedonecrosis present vs. absent) [15]. None of the randomized trials, however, required a surgical excision and a histopathologic work-up that would expect complete excision of the lesion according to its growth pattern.

Two trials are available that address the issue of margin width prospectively. Wong et al. [23] examined 158 patients with predominantly G1 or G2 lesions and a mammographic extent $\leq 2.5 \mathrm{~cm}$ in a single-institutional trial. All patients underwent wide excision alone. A margin width of $1 \mathrm{~cm}$ was required. The ipsilateral failure rate was $2.4 \%$ per patient year with a median follow-up time of 40 months. The calculated 5-year recurrence rate of $12 \%$ was considered too high so that the trial was stopped. The study is hampered by several methodological problems: The extent of the lesion was determined by mammography rather than histological assessment. A standardized protocol for the histopathologic examination including a complete work-up of the entire lesion is not available. Furthermore, a high rate of re-excisions (84\%!) was described, impeding precise margin assessment. In a prospective, single arm, multi-institutional trial, Hughes et al. [24] examined 565 patients with low or intermediate grade DCIS measuring $\leq 2.5 \mathrm{~cm}$ (histological extent), and patients with high grade lesions measuring $1 \mathrm{~cm}$ or smaller. In this study, a more detailed pathological assessment including sequential sectioning of the completely embedded specimen was performed. Margins of $\geq 3 \mathrm{~mm}$ were required. At a median follow-up of 6.2 years, the ipsilateral breast event rate was $6.1 \%$ for $\mathrm{G} 1$ and $\mathrm{G} 2$ lesions. The recurrence rate for $\mathrm{G} 3$ lesions was $15.3 \%$ at a median follow-up of 6.7 years. The authors conclude that rigorously evaluated and selected patients with low to intermediate grade DCIS and margins $3 \mathrm{~mm}$ or wider had an acceptably low rate of ipsilateral breast events at 5 years after excision alone without irradiation. The patients in this trial were, however, older than the usual me- dian age at diagnosis of DCIS (median 60 years), and the lesions were small (median $6 \mathrm{~mm}$ ). The margin width exceeded $5 \mathrm{~mm}$ in $71.5 \%$ of the patients. The increase in ipsilateral breast events beyond 5 years warrants caution regarding the clinical implications of the results.

\section{Surgery with or without Radiotherapy?}

$\mathrm{RT}$ reduces the rate of ipsilateral breast recurrences in unselected patients with DCIS, who are treated with BCT and undergo standard surgical procedures and routine tissue processing (LOE 1a). Retrospective analysis revealed a benefit for all examined subgroups of patients. RT is therefore a standard treatment for women with DCIS, who undergo BCT, and should be offered to most patients. There is some evidence from retrospective and prospective trials that supports the hypothesis that DCIS could be cured by complete surgical resection without any further adjuvant treatment. Standard surgical treatment and routine tissue processing, however, cannot ensure the complete removal of DCIS. This might explain the effect of adjuvant local and systemic treatment. DCIS is a local disease, and it seems apparent that recurrences depend on residual tumour foci in the breast (effect of margins). The probability of relapse and the time span to recurrence is probably associated with biologic behaviour. Since DCIS is not a life-threatening disease, and RT has (in contrast to invasive cancer) no impact on overall survival, it seems justifiable to omit RT in selected patients in whom residual occult tumour burden appears unlikely and the biological potential of the lesion to progress is estimated to be low. Patients should be informed about the specific benefit of RT and the need for mastectomy in the case of recurrence after irradiation.

\section{Extent of Surgery in Patients who Undergo BCT and Radiotherapy}

$\mathrm{BCT}$ and adjuvant RT is the standard of care for most patients with DCIS. The adequate surgical extent in these patients has not been defined in the past. In a meta-analysis including 4,660 patients from 22 trials, Dunne et al. [25] examined the effect of margin status on local recurrences for patients who underwent BCT and RT. The authors concluded that margin status (negative vs. positive, negative vs. close, negative vs. unknown) was an important predictor for recurrence even in patients who received RT after BCT. A margin width of $2 \mathrm{~mm}$ was as good as larger margins in this study. Although the analysis was retrospective in design and the number of patients with wide margins was very low ( $\geq 5 \mathrm{~mm}$ : 154 patients, $2 \mathrm{~mm}$ : 207 patients, $1 \mathrm{~mm}$ : 1,239 patients, no cells on ink: 914 patients), the study provides the best available evidence for the required margins in patients who undergo surgical excision and RT for DCIS. A re-excision is therefore no longer recom- 
mended for patients with margins $\geq 2 \mathrm{~mm}$, since the rate of re-excisions is an important quality indicator.

\section{Management of the Axilla in DCIS}

DCIS is a preinvasive lesion, and axillary staging is therefore not required as a standard procedure. Axillary metastasis due to the presence of unrecognized invasive disease is found in less than $5 \%$ of patients [26, 27]. Locoregional recurrences in patients who do not undergo axillary surgery are very low [28]. Most guidelines recommend sentinel lymph node biopsy (SLNB) in lesions $\geq 5 \mathrm{~cm}$ or in patients who undergo mastectomy. In these patients, a secondary SLNB (in the case of an unexpected invasive component) is technically not feasible because the integrity of the lymphatic drainage has been destroyed by the primary intervention [29]. Axillary dissection is restricted to patients with positive lymph nodes and is not indicated in pure DCIS.

\section{Systemic Treatment}

Tamoxifen is the only established systemic treatment for DCIS. Two prospective, controlled, randomised trials address the effect of adjuvant tamoxifen in patients who underwent BCT. NSABP B-24 [30] randomized 1,804 patients with lumpectomy and RT (50 Gy) to receive either placebo or tamoxifen (20 mg for 5 years). Patients with involved resection margins were included in the study. The rate of breast cancer events at 5 years was $8.2 \%$ in the tamoxifen group compared to $13.4 \%$ for patients who had received placebo. No difference in overall survival was observed. Significantly higher rates of side effects were registered for patients in the tamoxifen arm with regard to thromboembolic events, menstrual disorders, hot flashes, fluid retention and vaginal discharge. The UK, Australia and New Zealand trial [31] is a prospective, controlled, randomised trial with a $2 \times 2$ factorial design. Patients who had undergone complete surgical excision (defined as free margins on histological examination) received no adjuvant treatment, a combination of RT and tamoxifen, or RT or tamoxifen alone. At the San Antonio Meeting 2009, the updated data from this trial were presented [16]. Tamoxifen reduced the rate of all breast events after 10 years from 26.1 to $19.0 \%$ with a hazard ratio (HR) of 0.71 (0.58-0.88). There was no effect on ipsilateral invasive recurrences, and a small effect on DCIS recurrence (8.8 vs. $2.1 \%$, HR 0.78 (0.62-0.99)). Contralateral events decreased from 4.9 to $2.1 \%$ with a HR of $0.44(0.25-0.77)$. Interestingly, the effect of tamoxifen was more pronounced in low grade lesions compared to high grade lesions (HR 0.16 vs. 0.41 vs. 0.73 for low grade, intermediate grade and high grade lesions, respectively).

\section{Discussion}

Although DCIS represents a heterogenous group of lesions, it is a localized process with excellent survival rates. Local control is the primary therapeutic objective. Invasive breast cancer, in contrast, is a systemic, life-threatening disease. Survival is the primary treatment goal in these patients. While surgery (mastectomy) alone can provide an almost $100 \%$ cure rate in patients with DCIS, the same procedure is associated with local recurrences exceeding $20 \%$ in high-risk patients. This observation underlines the need for further systemic and local treatment in these patients [32].

The therapeutic index of adjuvant treatment is less favourable in DCIS than it is in invasive disease. While RT has a significant impact on overall survival in most subgroups of patients with invasive breast cancer, there is no survival benefit from RT in DCIS. Local recurrences from invasive breast cancer are reduced by $19.2 \%$ in node-negative and $33.4 \%$ in node-positive patients with BCT [32]. For DCIS, the absolute reduction of ipsilateral recurrences after 10 years varies from 11 to $16 \%[14,22]$. Since $\mathrm{RT}$ is not associated with a survival benefit and its effect on local control is less than for invasive disease, the therapeutic index for RT is far less favourable in DCIS than it is for invasive breast cancer. Although the measurable long-term toxicity of RT appears low [15], experience tells that reoperations in an irradiated breast are associated with a high rate of complications. Furthermore, patients with local recurrence after surgical excision and RT will require mastectomy. About $10-15 \%$ of all DCIS patients relapse even after BCT and RT. These patients could have been candidates for a second BCT but will undergo mastectomy due to the preceding RT. The benefit of RT in DCIS patients should therefore be weighed against possible disadvantages.

Five years of tamoxifen is associated with a 9.2 and $11.8 \%$ gain in overall survival and disease-free survival, respectively, in patients with invasive disease [33]. Patients with DCIS have no survival benefit from tamoxifen and no reduction in ipsilateral invasive recurrence after 10 years [16]. The absolute reduction of ipsilateral DCIS recurrences is 3.6\%. Contralateral events are reduced by $2.8 \%$ from 4.9 to $2.1 \%$. The therapeutic index of tamoxifen is certainly much less favourable for DCIS than it is for invasive cancer, taking into account its side effects of endometrial cancer, thromboembolic events, cataract, vaginal discharge, uterine bleeding and polyps. Although a statistically significant effect has been observed for tamoxifen in two randomised trials, it appears questionable if this effect is clinically beneficial. An adequate follow-up appears more appropriate in most patients, especially as treatment with tamoxifen is not associated with any survival benefit.

RT and tamoxifen can improve event-free survival in patients with DCIS. Both treatment modalities are, however, associated with an unfavourable therapeutic index compared to invasive disease. There is an urgent need for further studies to 
improve the treatment of DCIS and develop individual and targeted treatment strategies. It is certainly essential to gain further insights into the biological behaviour of different subtypes of DCIS, and define patients who can be spared from adjuvant treatment because their risk for relapse is low or absent. New biological agents may provide new treatment options, although the systemic approach has so far not yielded convincing results. Accelerated partial breast radiation is currently evaluated as a less burdensome alternative to whole breast irradiation [34].

Surgery has shown to be the most effective therapeutic option for DCIS. There are convincing data from retrospective trials that a complete surgical excision of DCIS is feasible with low recurrence rates, provided that a well defined diagnostic-therapeutic algorithm was respected. This concept takes into account the segmental and discontinuous growth pattern of DCIS. It requires wide margins of at least $10 \mathrm{~mm}$ and a histopathologic assessment that includes a complete work-up of the entire specimen in serial sections. None of the available prospective studies provided a design that would expect a complete resection of the entire lesion. Theoretical considerations suggest that a segmental resection and a histopathologic work-up in the mamilloperipheral axis could even improve the determination of the extent of a lesion and the assessment of margin width. This segmental concept has so far not been evaluated in prospective trials. Given the unfavourable therapeutic index for adjuvant treatment of DCIS today, the evaluation of an improved surgical approach deserves further evaluation and should be one strategy among others to search for a more targeted treatment of this complex lesion.

\section{Conflict of Interest}

The author declares no conflict of interests.

\section{References}

1 Frykberg ER, Bland KI: Overview of the biology and management of ductal carcinoma in situ of the breast. Cancer 1194;74:350-361.

$\checkmark 2$ Rosen PP, Braun DW, Kinne DE: The clinical significance of preinvasive breast carcinoma. Cancer 1980;46:919-925.

3 Eusebi V, Feudale E, Foschini MP, et al.: Longterm follow-up of in situ carcinoma of the breast. Semin Diagn Pathol 1994;11:223-235.

4 Caus EB, Sowe M, Carter D: Breast carcinoma in situ: risk factors and screening patterns $\mathrm{J}$ Natl Cancer Inst 2001;93:1811-1817.

5 Jemal A, Siegel R, Ward E: Cancer Statistics 2007. CA Cancer J Clin 2007;57:43.

6 Rosner D, Bedwani RN, Vana J, et al.: Noninvasive breast carcinoma: results of a national survey by the American College of Surgeons. Ann Surg 1980;192:139.

7 Ernster VL, Barclay J, Kerlikowske K, et al.: Mortality among women with ductal carcinoma in situ of the breast in the population based surveillance, epidemiology and end results program. Arch Intern Med 2000;160:953-958.

8 Solin LJ, Kurtz J, Fourquet A, et al.: Fifteen-year results of breast-conserving surgery and definite breast irradiation for the treatment of ductal carcinoma in situ of the breast. J Clin Oncol 2000;14:754-763.

9 Kuhl CK, Schrading S, Bieling HB, et al.: MRI for diagnosis of pure ductal carcinoma in situ: a prospective observational study. Lancet 2007;370:485492.

$\checkmark 10$ Lee CH, Dershaw DD, Kopans D, Evans P, Monsees B, Monticciolo D, Brenner RJ, Bassett L, Berg W, Feig S, Hendrick E, Mendelson E, D'Orsi C, Sickles E, Burhenne LW: Breast cancer screening with imaging: recommendations from the Society of Breast Imaging and the ACR on the use of mammography, MRI, breast ultrasound and other technologies for the detection of clinically occult breast cancer. J Am Coll Radiol 2010;7:18-27.
11 Allen LR, Lago-Toro CE, Hughes JH, Careaga E, Brown AT, Chernick M, Barrio AV, Frazier TG: Is there a role of MRI in the preoperative assessment of patients with DCIS? Ann Surg Oncol 2010;Epub ahead of print.

12 Silverstein MJ, Lagios MD, Groshen S, Waisman JR, Lewinsky BS, Martino S, Gamagami P, Colburin WJ: The influence of margin width on local control of ductal carcinoma in situof the breast. N Engl J Med 1999;340:1455-1461.

13 Fisher B, Dignam J, Wolmark N, Mamounas E, Costantino J, Fisher B, Paik S, et al.: Lumpectomy and radiation therapy for the treatment of intraductal breast cancer: findings from National Surgical Adjuvant Breast and Bowel Project B-17. J Clin Oncol 1998;16:441-452.

14 Bijker N, Meijnen P, Peterse JL, Bogaerts J, Van Hoorebeeck I, Julien JP, Genaro M, Rouanet P, Avril A, Fentiman IS, Bartelink H, Rutgers EJT: Breast conserving treatment with or without radiotherapy in ductal carcinoma in situ: ten year results of European Organisation for Research and Treatment of Cancer Randomized Phase trial 10853 - a study by the EORTC Breast Cancer Cooperative Group and EORTC Radiotherapy group. J Clin Oncol 2006;24:3381-3387.

15 Goodwin A, Parker S, Ghersi D, Wilcken N: Postoperative radiotherapy for ductal carcinoma in situ of the breast - a systematic review of the randomized trials. Breast 2009;18:143-149.

16 Cuzik J, Sestak I, Pinder SE, Ellis IO, Hackshaw A, bundred NJ, Forbes JF, Bishop H, Fentiman IS, George WD: Beneficial effect of tamoxifen for women with DCIS: long-term results from the UK/ANZ DCIS trial in women with locally excised DCIS. Cancer Res 2009;69(suppl):34.

17 Allred DC, Bryant J, Land S, et al.: Estrogen receptor expression as a predictive marker of the effectiveness of tamoxifen in the treatment of DCIS: findings from NSABP protocol B-24. Breast Cancer Res Treat 2002;76:36.
18 Silverstein MJ, Barth A, Poller DN: Ten year results comparing mastectomy to excision and radiation therapy for ductal carcinoma in situ of the breast. Eur J Cancer 1995;31A:1425-1427.

19 Shouten van der Velden AP, van Vugt R, Van Dijck JA, et al.: Local recurrences after different treatment strategies for ductal carcinoma of the beast: a population based study in the East Netherlands. Int J Radiat Oncol Biol Phys 2007;69:703-710.

20 Faverly DR, Burgers L, Bult P, Holland R: Three dimensional imaging of mammary ductal carcinoma in situ: clinical implications. Semin Diagn Pathol 1994;11:193.

21 Houghton J, George WD, Cuzick J, Duggan C, Fentiman IS, Spittel M, et al.: Radiotherapy and tamoxifen in women with completely excised ductal carcinoma in situ of the breast in the UK, Australia and New Zealand: a randomized controlled trial. Lancet 2003;362:95-102.

22 Holmberg L, Garmo H, Granstrand B, Ringberg A, Arnesson LG, Sandelin K, et al.: Absolute risk reductions for local recurrence after postoperative radiotherapy after sector resection for ductal carcinoma in situ of the breast. J Clin Oncol 2008;26:1247-1252.

23 Wong JS, Kaelin CM, Troyan SL, Gadd MA, Gelman R, Lester SC, Schnitt SJ, Sgroi DC, Silver BJ, Harris JR, Smith BL: Prospective study of wide excision alone for ductal carcinoma in situ of the breast. J Clin Oncol 2006;24:1031-1036.

24 Hughes LL, Wang M, Page DL, Gray R, Solin LJ, Davidson NE, Lowen LA, Ingle JN, Recht A, Wood WC: Local excision alone without irradiation for ductal carcinoma in situ of the breast: a trial of the Eastern Cooperative Oncology Group. J Clin Oncol 2009;27:5319,5324.

25 Dunne C, Burke JP, Morrow M, Kell MR: Effect of margin status on local recurrence after breast conservation and radiation therapy for ductal carcinoma in situ. J Clin Oncol 2009;27:1615-160. 
26 Winchester DP, Menck HR, Osteen RT, Kraybill W: Treatment trends for ductal carcinoma in situ of the breast. Ann Surg Oncol 1995;2:207.

27 Inta M, Veronesi P, Mazzarol G, et al.: Axillary sentinel lymph node biopsy in patients with pure ductal carcinoma in situ of the breast. Arch Surg 2003;138:309.

28 Julian TB, Land SR, Fourchote V, et al.: Is sentinel node biopsy necessary in conservatively treated DCIS? Ann Surg Oncol 2007;23:7703.

29 Kühn T, Bembenek A, Decker T, Munz DL, Sautter-Bihl ML, Untch M, Wallwiener D: Consensus Committee of the German Society of Senology. A concept for the clinical implementation of sentinel lymph node biopsy (SLNB) in breast cancer patients with special regard to quality assurance. Cancer 2005;103:451-461.
30 Fisher B, Dignan J, Wolmark N, Wickerman DL, Fisher ER, Mamounas E, Smith R, Beqovic M, Dimitrov NV, Margolese RG, Kardinal CG, Kavanah MT, Fehrenbacher L, Oishi RH: Tamoxifen in treatment of intraductal breast cancer: National Surgical Adjuvant Breast and Bowel Project B-24 randomised controlled trial. Lancet 1999;353:1993-2000.

31 UK Coordinating Committee on Cancer Research (UKCCCR): Ductal carcinoma in situ (DCIS) working party on behalf of DCIS trialists in the UK, Australia and New Zealand. Lancet 2003;362:95-102.
32 Early Breast Cancer Trialists Collaborative Group (EBCTCG): Effect of radiotherapy and of differences in the extent of surgery for early breast cancer on local recurrences and 15-year survival: an overview of the randomised trials. Lancet 2005;366:2087-2106.

33 Early Breast Cancer Trialists Collaborative Group (EBCTCG): Effect of chemotherapy and hormonal therapy for early breast cancer on recurrence and 15-year survival: an overview of the randomised trials. Lancet 2005;365:1687-1717.

4 Jeruss JS, Vicini FA, Beitsch PD, et al.: Initial outcomes for patients treated on the American Society of Breast Surgeons Mammosite clinical trial for ductal carcinoma in situ of the breast. Ann Surg Oncol 2006;13:967-976. 